\title{
MOTIVASI KELUARGA DALAM PEMANFAATAN PUSKESMAS BAGI ANGGOTA KELUARGA YANG SAKIT DI DESA BAKARAN BATU DUSUN V LUBUK PAKAM
}

\author{
Lenny Lusia Simatupang \\ Program Studi Ilmu Keperawatan, STIKes Murni Teguh \\ E-mail : lennylusia30@gmail.com
}

\begin{abstract}
Health centers have a role in improving the quality of health services to the community. The distance between the puskesmas and the residents' residences as well as inadequate medical equipment affects people's motivation to come for treatment. The purpose of this study was to determine the motivation of families in the use of the Puskesmas for sick family members. This research is a quantitative research using a descriptive approach. The types of data used in this study are primary data and secondary data. The sample in this study amounted to 48 people who were selected by purposive sampling technique and the respondents were the heads of families residing in the village of Bakaran Batu Dusun V Lubuk Pakam. The results of the study were analyzed by univariate analysis by describing descriptively the frequency distribution and proportion of each variable. Family motivation in using the puskesmas for sick family members showed that the majority of respondents had a low level of motivation. Low family motivation is influenced by several factors, namely based on trust, facilities, distance and availability of health workers
\end{abstract}

Keywords : Motivation, Family, Utilization of Puskesmas

\begin{abstract}
Abstrak
Puskesmas mempunyai peran dalam hal peningkatan mutu pelayanan kesehatan kepada masyarakat. Jarak puskesmas dengan tempat tinggal penduduk serta peralatan kesehatan yang tersedia tidak memadai mempengaruhi motivasi masyarakat untuk datang berobat. Tujuan dari penelitian ini untuk mengetahui motivasi keluarga dalam pemanfaatan Puskesmas bagi anggota keluarga yang sakit. Penelitian ini adalah penelitian kuantitatif dengan menggunakan pendekatan deskripstif. Jenis data yang digunakan dalam penelitian ini adalah data primer dan data sekunder. Sampel dalam penelitian ini berjumlah 48 orang yang dipilih dengan teknik purpossive sampling dan responden merupakan kepala keluarga yang berada di desa Bakaran Batu Dusun V Lubuk Pakam. Hasil penelitian dianalisis dengan analisa univariat dengan menjabarkan secara deskriptif distribusi frekuensi dan proporsi masing-masing variabel. Motivasi keluarga dalam pemanfaatan puskesmas bagi anggota keluarga yang sakit didapatkan hasil bahwa mayoritas responden memiliki tingkat motivasi yang rendah. Motivasi keluarga yang rendah dipengaruhi oleh beberapa faktor yaitu berdasarkan kepercayaan, fasilitas, jarak dan ketersediaan tenaga kesehatan.
\end{abstract}

Kata kunci : Motivasi, Keluarga, Pemanfaatan Puskesmas

\section{PENDAHULUAN}

Puskesmas merupakan unit pelayanan kesehatan yang menyelenggarakan upaya kesehatan yang bersifat terpadu, menyeluruh dan merata. Keberhasilan pelayanan kesehatan dipengaruhi oleh berbagai faktor antara lain ketersediaan dan mutu fasilitas pelayanan kesehatan, perbekalan kesehatan, ketersediaan obat, manajemen kesehatan, yang terutama adalah tenaga kesehatan sebagai ujung tombak pelayanan (Siregar, 2018).

Sub sistem dalam pelayanan kesehatan yaitu dimulai dari keluarga 
sehingga keluarga mempunyai peranan penting dalam akses pelayanan kesehatan. Motivasi keluarga dalam memanfaatkan pelayanan di puskesmas dipengaruhi dengan berbagai faktor yaitu faktor kepercayaan, keyakinan, pengetahuan, persepsi, nilai, keterjangkauan biaya, jarak dan fasilitas transportasi, sikap dan perilaku petugas kesehatan. Puskesmas merupakan tulang punggung dalam menyelenggarakan upaya pelayanan kesehatan dasar bagi masyarakat di wilayah kerjanya dan berperan dalam menyelenggarakan upaya kesehatan untuk meningkatkan kesadaran, kemauan dan kemampuan hidup sehat bagi setiap penduduk agar penduduk dapat memperoleh derajat kesehatan yang optimal, sehingga untuk melaksanakan upaya kesehatan baik upaya kesehatan masyarakat tingkat pertama dan upaya kesehatan perseorangan tingkat pertama. (Pusdatin, 2016).

Dalam kehidupan sehari hari pemanfaatan puskesmas belum maksimal. Keadaan ini dapat dilihat dari berbagai data provinsi kunjungan puskesmas kurang dari 6 $\%$ antara lain : Sumatera Utara (5.8\%), Banten (5,7\%), Kalimantan Tengah $(5,7 \%)$, Riau (5.5\%) dimana penduduk yang mayoritas tidak menggunakan puskesmas adalah penduduk pedesaan (Pusdatin, 2012). Data dari profil kesehatan Sumatera Utara tahun 2012, jumlah puskesmas perawatan sebanyak 163 unit, puskesmas keliling 522 unit. Puskesmas yang berada di Lubuk Pakam tercatat 11 jumlah puskesmas yang memberikan pelayanan kesehatan dasar. Persentase penduduk yang memanfaatkan puskesmas tersebut adalah $18,87 \%$, jumlah ini menurun dari tahun 2011.

Masalah pelayanan kesehatan menjadi pusat perhatian dan perlu ditindaklanjuti. Dapat diperkirakan masih 35 $\%$ penduduk Indonesia memanfaatkan fasilitas pelayanan kesehatan sehingga dapat mempengaruhi derajat kesehatan masyarakat (Riskesdas, 2018). Hasil penelitian Maelissa \& Lilipory 2020 mengatakan adanya berbagai alasan responden tidak mau berkunjung ke falititas kesehatan adalah karena peralatan kesehatan dimana peralatan tidak memadai hanya seadanya untuk mengobati penyakit seperti pilek, batuk, akan tetapi untuk melakukan pemeriksaan yang lebih lanjut tidak bisa. Alasan berikutnya adalah adanya prinsip dimasyarakat bahwa ibu hamil tidak dizinkan mendapat suntik sehingga ibu hamil tidak melakukan pemeriksaan kesehatan. Kebutuhan lain yang diharapkan oleh keluarga dalam dalam mengurus orang sakit adalah mengharapkan adanya dukungan dari sosial dan juga dari nilai-nilai tradisional yang ada pada budaya salah satunya adalah pada budaya Batak Toba (Simatupang, 2015). Tehnik dan cara penyembuhan yang alami adalah merupakan bagian dari strategi holistic self care (Simatupang \& Sinaga, 2020)

Alasan lain yang menyebabkan masyarakat tidak datang memeriksakan kesehatannya ke puskesmas dan memutuskan untuk memilih berobat ke fasilitas pelayanan kesehatan lainnya yaitu ke praktek dokter atau praktek bidan adalah karena jarak rumah dengan puskesmas jauh dan kurangnya informasi terkait pelayanan kesehatan, faktor kesibukan bekerja dan mencari nafkah (Dwianty, 2010).

\section{METODE PENELITIAN}

Jenis penelitian ini adalah penelitian kuantitatif yang menggunakan pendekatan deskriptif. Desain ini digunakan untuk mengetahui motivasi keluarga dalam pemanfaatan puskesmas bagi anggota keluarga yang sakit. Penelitian dilakukan di dusun V desa Bakaran Batu Lubuk Pakam pada bulan Desember 2020 dengan populasi sejumlah 240 orang kepala keluarga. Responden dalam penelitian ini dipilih melalui tehnik purposive sampling, dimana tehnik penetapan sampel ini dengan cara memilih sampel di antara populasi sesuai dengan yang dikehendaki peneliti, maka sampel dalam penelitian ini sebanyak 48 orang.

Pengumpulan data dilakukan dengan cara pendekatan terhadap subjek dan pengumpulan karakteristik subjek dengan tehnik pengumpulan data primer dan sekunder. Data primer diperoleh langsung 
dari jawaban responden atas pertanyaan yang diajukan melalui kuesioner tentang motivasi keluarga dalam pemanfaatan puskesmas bagi anggoata keluarga yang sakit. Data sekunder diperoleh dari desa Bakaran Batu Dusun V Lubuk Pakam yang berkaitan dengan jumlah kepala keluarga yang ada di desa tersebut dan data pendukung lainnya. Karakteristik responden dan motivasi keluarga dianalisa dengan uji analisa statistik menggunakan program komputer dan disajikan dalam bentuk tabel distribusi frekuensi.

\section{HASIL PENELITIAN}

Responden dalam penelitian ini berjumlah 48 orang kepala keluarga yang pernah mengalami sakit selama enam bulan terakhir. Jumlah responden yang berusia 2837 tahun adalah 7 orang (15\%), 38-47 tahun adalah 26 orang (54\%), 48-65 tahun adalah 15 orang $(31 \%)$. Pendidikan dari responden yaitu SD 8 orang (17\%), SMP 19 orang $(40 \%)$, SMA 18 orang (37\%), diploma/sarjana 3 orang (6\%). Pekerjaan responden adalah Wiraswasta 27 orang $56 \%$, Pegawai swasta 8 orang 17\%, PNS 2 orang $4 \%$, IRT 2 orang 4\%, Petani 9 orang $19 \%$. Karakteristik responden secara rinci akan dijelaskan dibawah ini.

Tabel 1. Karakteristik Responden

\begin{tabular}{lcc}
\hline $\begin{array}{l}\text { Data Demografi } \\
\text { Responden }\end{array}$ & f & Persentase \% \\
\hline Usia & & \\
$28-37$ & 7 & $15 \%$ \\
$38-47$ & 26 & $54 \%$ \\
$48-65$ & 15 & $31 \%$ \\
\hline$\quad$ Jumlah & 48 & $100 \%$ \\
\hline Pendidikan & & \\
SD & 8 & $17 \%$ \\
SMP & 19 & $40 \%$ \\
SMA & 18 & $37 \%$ \\
Diploma/ Sarjana & 3 & $6 \%$ \\
\hline Jumlah & 48 & $100 \%$ \\
\hline Pekerjaan & & \\
Wiraswasta & 27 & $56 \%$ \\
Pegawai swasta & 8 & $17 \%$ \\
PNS & 2 & $4 \%$ \\
IRT & 2 & $4 \%$ \\
Petani & 9 & $19 \%$ \\
\hline Jumlah & 48 & $100 \%$ \\
\hline
\end{tabular}

Hasil penelitian dapat dilihat dari motivasi keluarga dalam pemanfaatan puskesmas berdasarkan pelayanan, berdasarkan fasilitas, berdasarakan jarak, berdasarkan keramahtamahan petugas.

Tabel 2. Distribusi Frekuensi Hasil Penelitian Motivasi Keluarga dalam Pemanfaatan Puskesmas berdasarkan Kepercayaan

\begin{tabular}{lcc}
\hline Motivasi keluarga & f & Persentase \% \\
\hline Rendah & 27 & $56.25 \%$ \\
Sedang & 11 & $22.9 \%$ \\
Tinggi & 10 & $20.8 \%$ \\
\hline \multicolumn{1}{c}{ Jumlah } & 48 & $100 \%$ \\
\hline
\end{tabular}

Motivasi keluarga dalam pemanfaatan puskesmas bagi anggota keluarga yang sakit di desa Bakaran Batu Dusun V Lubuk Pakam berdasarkan kepercayaan adalah Motivasi keluarga dalam pemanfaatan puskesmas yang rendah 27 $(56.25 \%)$, responden motivasi keluarga dalam pemanfaatan puskesmas yang Sedang $11(22.9 \%)$, responden motivasi keluarga dalam pemanfaatan puskesmas yang tinggi 10 (20.8\%). Motivasi keluarga dalam pemanfaatan puskesmas dari kepercayaan yang dirasakan oleh masyarakat adalah mayoritas rendah dan minoritas tinggi.

Tabel 3 Distribusi Frekuensi Hasil Penelitian Motivasi Keluarga dalam Pemanfaatan Puskesmas Berdasarkan Fasilitas

\begin{tabular}{ccc}
\hline Motivasi keluarga & f & Persentase \% \\
\hline Rendah & 23 & $48 \%$ \\
Sedang & 18 & $37.5 \%$ \\
Tinggi & 7 & $14.5 \%$ \\
\hline Jumlah & $\mathbf{4 8}$ & $\mathbf{1 0 0 \%}$ \\
\hline
\end{tabular}

Motivasi keluarga dalam pemanfaatan Puskesmas berdasarkan fasilitas di tingkat rendah sebanyak 23 responden (48\%), sedang sebanyak 18 responden $(37.5 \%)$, tinggi sebanyak 7 responden (14.5\%). Motivasi keluarga dalam pemanfaatan puskesmas berdasarkan fasilitas mayoritas rendah dan minoritas tinggi. 
Tabel 4. Distribusi Frekuensi Motivasi Keluarga dalam Pemanfaatan Puskesmas Berdasarkan Jarak

\begin{tabular}{ccc}
\hline Motivasi keluarga & f & Persentase \% \\
\hline Rendah & 26 & $54.1 \%$ \\
Sedang & 13 & $27 \%$ \\
Tinggi & 9 & $19 \%$ \\
\hline Jumlah & $\mathbf{4 8}$ & $\mathbf{1 0 0 \%}$ \\
\hline
\end{tabular}

Dari tabel diatas terlihat bahwa motivasi keluarga dalam pemanfaatan puskesmas berdasarkan jarak yaitu rendah sebanyak 26 responden (54.1\%), sedang 13 responden (27\%), tinggi 9 responden (19\%). Motivasi keluarga memanfaatkan puskesmas berdasarkan jarak mayoritas rendah dan minoritas tinggi.

Tabel 5. Distribusi Frekuensi Hasil Penelitian Motivasi dalam Pemanfaatan Puskesmas Berdasarkan Ketersediaan Tenaga Kesehatan

\begin{tabular}{ccc}
\hline Motivasi keluarga & f & Persentase\% \\
\hline Rendah & 19 & $40 \%$ \\
Sedang & 8 & $17 \%$ \\
Tinggi & 21 & $43 \%$ \\
\hline Jumlah & $\mathbf{4 8}$ & $\mathbf{1 0 0 \%}$ \\
\hline
\end{tabular}

Berdasarkan tabel diatas menunjukkan bahwa motivasi keluarga dalam pemanfaatan puskesmas berdasarkan kerahtamahan petugas yaitu motivasi rendah 19 responden (40\%), motivasi sedang yaitu 8 responden (17\%), motivasi tinggi 21 responden $(43 \%)$. Motivasi keluarga dalam pemanfaatan puskesmas berdasarkan ketersediaan petugas kesehatan mayoritas tinggi dan minoritas sedang.

\section{PEMBAHASAN}

Motivasi keluarga dalam pemanfaatan puskesmas berdasarkan kepercayaan, didapatkan hasil penelitian sebagian besar keluarga mempunyai motivasi rendah yaitu 27 responden sebanyak 56.25 $\%$. Hal ini sejalan dengan hasil penelitian Anwar et al. (2019) dimana responden rendah dalam pemanfaatan puskesmas karena lebih percaya menggunakan pengobatan alternatif yaitu seperti pengobatan tradisional ritual belian, pengobatan nyengok, betawar dan ramuan-ramuan dengan memanfaatkan tumbuhan-tumbuhan. Hal ini didukung oleh hasil penelitian Ginting et al (2019) untuk mengatasi masalah kesehatan banyak memilih tindakan non-farmakologis karena relative murah, seperti aromatherapy lemon sebagai alternatif dalam mengurangi nyeri persalinan kala II. Cakupan pengobatan yang dimanfaatakan oleh masyarakat bersumber dari tiga sektor utama antara lain pengobatan dengan memanfaatkan pengobatan tradisional, menggunakan pengobatan sendiri, pengobatan rumah tangga dan mencari pengobatan medis yang dilakukan oleh dokter, perawat di puskesmas maupun di rumah sakit (Rahayu, 2012). Kepercayaan berkaitan dengan hubungan dengan antara petugas dan pasien. Dimana faktor yang dapat berpengaruh pada pemanfaatan pelayanan kesehatan adalah tingkat keyakinan terhadap pelayanan kesehatan yang diberikan. Hubungan yang baik dapat menumbuhkan kepercayaan dan motivasi dengan cara menghargai yang dapat dilihat melalui penerimaan, kepercayaan, empati, menjaga rahasia, menghormati serta memberikan perhatian terhadap pasien.

Motivasi keluarga dalam pemanfaatan puskesmas berdasarkan fasilitas, didapatkan hasil penelitian sebagian besar keluarga mempunyai motivasi rendah dalam pemanfaatan Puskesmas yaitu sebanyak 23 responden atau $48 \%$. Fasilitas yang ada di dalam pelayanan kesehatan merupakan salah satu faktor dalam meningkatkan motivasi masyarakat untuk datang berobat. Hasil penelitian Maelissa \& Lilipory (2020) bahwa alasan responden sehingga tidak menggunakan fasilitas kesehatan adalah karena peralatan yang tersedia tidak memadai, hanya seadanya untuk mengobati batuk, pilek.

Motivasi keluarga dalam pemanfaatan Puskesmas berdasarkan jarak, didapatkan hasil penelitian sebagian besar keluarga mempunyai motivasi rendah yaitu 26 responden sebanyak 54,1 \%. Jarak fasilitas kesehatan dengan rumah penduduk merupakan salah satu alasan masyarakat untuk tidak datang ke Puskesmas. 
Keterjangkauan yang dimaksud adalah waktu tempuh yang lama, kemudahan transportasi untuk mencapai pelayanan kesehatan. Hal ini sejalan dengan hasil penelitian Pobela \& Kanine (2018) sebagian besar responden yang menderita hipertensi mengatakan bahwa jarak puskesmas dengan desa Kobo Kecil cukup jauh sehingga mereka lebih memilih fasilitas pelayanan kesehatan yang paling dekat. Meskipun didesa tersebut tersedia alat transportasi dan sebagian dari responden memiliki kendaraan pribadi seperti motor tapi tetap tidak termotivasi untuk menggunakan puskesmas sebagai fasilitas kesehatan.

Motivasi keluarga dalam pemanfaatan puskesmas berdasarkan ketersediaan tenaga kesehatan, didapatkan hasil penelitian sebagian besar keluarga mempunyai motivasi yang tinggi yaitu 21 responden sebanyak $43 \%$. Hasil penelitian sejalan dengan dengan hasil penelitian yang dilakukan oleh Maryati et al. (2018) di Puskesmas Tanah Sarel Kota Bogor dimana sebagian besar responden melakukan pemanfaatan pelayanan kesehatan di Puskesmas dapat dilihat dari 110 responden menyatakan $76 \quad(69,1 \%)$ memanfaatkan Puskesmas. Keadaan ini dapat disebabkan oleh karena masyarakat menilai puskesmas Tanah Sareal memiliki ketersediaan tenaga kesehatan yang mampu memberikan solusi bagi masalah kesehatannya. Petugas kesehatn memiliki pengaruh dalam memotivasi masyarakat untuk menggunakan fasilitas kesehatan yang ada di Puskesmas. Pengaruh dapat berupa dukungan petugas kesehatan yang dapat menjadi faktor pendorong, dukungan tersebut berupa informasi seperti memberikan penyuluhan-penyuluhan kepada masyarakat dari petugas kesehatan yang tersedia untuk memanfaatkan layanan yang ada di Puskesmas contohnya adalah melakukan pemeriksaan secara sukarela bahkan mencari pengobatan dan perawatan (Hamzah et al, 2020). Dengan memberikan informasi baik melalui media cetak dan media elektronik akan menambah tingkat pengetahuan tentang kesehatan (Simatupang, 2018).
Pendidikan kesehatan merupakan suatu bimbingan yang diberikan seseorang kepada orang lain sehingga dapat mengarahkan manusia dalam berbuat untuk meningkatkan kesehatanny. Dalam Permenkes RI Nomor 75 Tahun 2014 Tentang Puskesmas tenaga kesehatan merupakan setiap orang yang mengabdikan diri dalam bidang kesehatan dan mempunyai pengetahuan dan atau keterampilan melalui kewenangan untuk melakukan upaya pelayanan di bidang kesehatan. Sumber daya manusia yang ada di Puskesmas terdiri atas Tenaga Kesehatan dan tenaga non kesehatan. Jenis dan jumlah tenaga kesehatan dan tenaga non kesehatan dapat dihitung berdasarkan analisis beban kerja, dengan mempertimbangkan jumlah pelayanan yang diselenggarakan, jumlah penduduk dan persebarannya, karakteristik wilayah kerja, luas wilayah kerja, ketersediaan fasilitas pelayanan kesehatan tingkat pertama di wilayah kerjanya

\section{KESIMPULAN}

Berdasarkan hasil penelitian yang telah dilakukan dapat disimpulkan sebagai berikut :

1. Karakteristik responden dalam motivasi pemanfaatan puskesmas dilihat dari usia mayoritas berusia 38-47 tahun (54\%), dilihat dari Pendidikan mayoritas responden berpendidikan SMP yaitu 19 orang $(40 \%)$, dilihat dari pekerjaan mayoritas bekerja sebagai wiraswasta yaitu sebanyak 27 orang (56\%).

2. Nilai motivasi keluarga dalam pemanfaatan Puskesmas berdasarkan kepercayaan keluarga mayoritas mempunyai motivasi rendah yaitu sejumlah 27 orang $(56.25 \%)$.

3. Nilai motivasi keluarga dalam pemanfaatan puskesmas berdasarkan fasilitas mayoritas rendah sebanyak 23 responden $(48 \%)$.

4. Motivasi keluarga dalam pemanfaatan puskesmas berdasarkan jarak anatar puskesmas dengan tempat tinggal penduduk mayoritas mempunyai motivasi rendah sebanyak 26 responden (54.1\%). 
5. Motivasi keluarga dalam pemanfaatan fasilitas puskesmas dilihat dari ketersediaan tenaga kesehatan mayoritas mempunyai motivasi tinggi yaitu sebanyak 21 responden (43\%).

\section{SARAN}

1. Fasilitas Kesehatan

Disarankan bagi fasilitas kesehatan (Puskesmas) agar dapat meningkatkan kepercayaan masyarakat untuk menggunakan falitas puskesmas dengan cara memberikan penyuluhan-penyuluhan kesehatan kepada masyarakat, melengkapi fasilitas yang ada di puskesmas.

2. Pemerintah

Disarankan kepada pemerintah agar menambah fasilitas puskesmas sehingga jarak antara rumah penduduk dengan fasilitas kesehatan tidak jauh sehingga masyarakat mempunyai motivasi yang tinggi untuk memanfaatkan fasilitas puskesmas.

3. Masyarakat

Disarankan kepada masyarakat agar meningkatkan motivasi dalam pemanfaatan puskesmas karena puskesmas merupakan fasilitas pelayanan kesehatan yang berupaya untuk meningkatkan derajat kesehatan masyarakat tingkat pertama dan lebih mengutamakan upaya pelayanan promotif dan preventif sehingga tercapai derajat kesehatan masyarakat yang setinggitingginya di wilayah kerja puskesmas.

4. Pelayanan Keperawatan

Bagi pelayanan keperawatan diharapkan dapat memberi pelayanan dengan rasa empati yang sangat besar

\section{REFERENSI}

Anwar, A., Ramdan, M.I., \& Lestari., E.D. (2019). Analisis pemanfaatan pelayanan kesehatan di puskesmas dempar kecamatan nyuatan kabupaten kutai barat. Jurnal Kesehatan, 5(1) 13-17

Dwiyanti,R. (2010) Gambaran faktor-faktor yang mempengaruhi Pemanfaatan puskesmas liu kecamatan sabbangparu kabupaten wajo. Diperoleh tanggal 28 desember 2020 di http://repositori.uin-alauddin.ac.id /3584/1/IRMA\%20DWIANTY.pdf

Ginting, L., Masta, M.H., \& Simatupang, L.L. (2019). Efektifitas aromatherapy lemon terhadap pengurangan nyeri persalinan, lama persalinan kala II dan fetal outcome. Jurnal Kebidanan Kestra.2(1).44-50

Hamzah, W., Amelia, R.A., Rahmah, H. (2020). Faktor yang berhubungan dengan pemanfaatan pelayanan kesehatan peduli remaja di SMA Muhammadiyah 7 Makassar. 1(2):111-120.

Maelisa, R. S., \& Lilipory, M. (2020) Persepsi keluarga dalam memanfaatkan fasilitas pelayanan kesehatan. Jurnal Keperawatan 12 (4): 807-814

Maryati,H., Shaputra, R., Hidana, R.(2018). Faktor-faktor yang berhubungan dengan pemanfaatan pelayanan kesehatan oleh pasien luar wilayah di puskesmas tanah sarel kota Bogor Tahun 2018. Jurnal Mahasiswa Kesehatan Masyarakat , 1(2) 105115

Pobela, N., \& Kanine, E. (2018). Motivasi penderita hipertensi di desa kobo kecil memanfaatkan pelayanan kesehatan di puskesmas kota Bangun. Di akses pada tangal 23 Desember $2020 \quad d i$ file:///C:/Users/Lenovo/AppData/Loc al/Temp/20714-42117-1-SM.pdf

Pusdatin Kemenkes (2016) Pusat data dan informasi Kementerian Kesehatan. Di peroleh pada tanggal 27 Desember $2020 \quad d i$ https://pusdatin.kemkes.go.id/resourc es/download/pusdatin/profil-kese hatan-indonesia/Profil-KesehatanIndonesia-2016.pdf

Pusdatin Kemenkes (2012) Pusat data dan informasi Kementrian Kesehatan Republik Indonesia daerah provinsi Sumatera Utara. Diperoleh pada tanggal 28 Desember $2020 \mathrm{di}$ 
https://pusdatin.kemkes.go.id/resourc es/download/profil/PROFIL_KES_P ROVINSI 2012/02 Profil Kes Prov SumateraUtara_2012.pdf

Rahayu, A. D. (2012) Faktor-faktor yang berhubungan dengan pemilihan pengobatan tradisional di wilayah kerja puskesmas muara siberut kecamatan siberut selatan kabupaten Kepulauan Mentawai Tahun 2012. Di peroleh tanggal 28 Desember 2020 di http://repository.unand. ac.id/20158/1/jurnal.pdf.

Riskesdas (2018) Riset kesehatan dasar Kementerian Kesehatan Republik Indonesia. Diperoleh pada tanggal $28 \quad$ Desember 2020 dihttps://kesmas.kemkes.go.id/assets/ upload/dir_519d41d8cd98f00/files/H asil-riskesdas-2018_1274. pdf

Simatupang, L, L. (2015) Pengalaman pasien suku batak toba dengan gagaj ginjal kronis dalam menjalani hemodialisa. Idea Nursing Journal, 6(3).19-26

Simatupang,L, L. (2018) Tingkat pengetahuan remaja putri tentang kesehatan reproduksi di SMA negeri Bahorok tahun 2017. Excellent Midwifery Journal, 1(2):73-7

Simatupang, L, L., \& Sinaga M. R.(2020) Pengaruh akupresur dan Latihan Napas Dalam Terhadap Fatigue dan Kualiats Tidur Pasien Hemodialisa di Murni Teguh Memorial Hospital, 5(1).56-60

Siregar, N. K., Romadhona, S. Y. (2018) Analisis sebaran tenaga kesehatan puskesmas di indonesia berdasarkan peraturan menteri kesehatan no 75 tahun 2014 tentang puskesmas. Jurnal Kesehatan Manarang 4(2): 114-121 